\title{
Working towards a Model of Intercultural Communicative Competence for Advanced-level EFL Learners
}

\author{
Judit Dombi \\ Department of English Linguistics, University of Pécs, Hungary \\ dombi.judit@pte.hu
}

\section{Introduction}

The idea that foreign language teaching (FLT) should prepare language learners for communication in real life situations is not new: over the past four decades research has focused on how to help language learners function as competent communicators in interactions with partners of various language and cultural backgrounds. For successful communication in the globalized world, it is no longer sufficient to master a linguistic code in order to exchange ideas and negotiate meaning. Language users need to be able to apply their knowledge, attitudes, skills and critical awareness (Byram, 1997) that help them in situations where the other parties are likely to have beliefs, ideologies, values and practices markedly different from their own. This need has been recognized by policy makers: the Common European Framework of Reference for Languages (Council of Europe, 2001, pp. 103-105) includes intercultural awareness and intercultural skills under general competences language learners should attain. Intercultural awareness and intercultural skills are widely referred to in FLT contexts as intercultural communicative competence (ICC) (Byram, 1997), a term emphasizing a link between the construct and established trends in FLT.

Individual differences that characterize language learners play an important role in how learners behave and interact in intercultural encounters. Thus, the complexity of the learner and of the language learning process also need to be taken into consideration. The world is perplexing and ever changing, as well as individuals: the differences characterizing learners and making them distinct from one another add to the intricacy of the issue. The past experiences, fears, expectations, motives, beliefs and attitudes learners bring to intercultural interactions play a role as important and conducive to their success as are their competences.

\section{An overview of the literature on ICC and individual differences}

\subsection{Intercultural Communicative Competence}

The most often quoted model of intercultural communicative competence was proposed by Byram (1997). In his conceptualization, ICC is made up of discourse competence, sociolinguistic competence, strategic competence and intercultural competence. The first three competences were introduced in applied linguistics (Canale, 1983; Canale \& Swain, 1980; van Ek, 1986). The fourth constituent, intercultural competence, comprises (1) attitudes, (2) knowledge, (3) skills, and (4) critical cultural awareness (Byram, 1997). 
The increased interest in intercultural interactions has resulted in numerous empirical studies on how individuals behave, communicate and eventually, cope in these interactions. Some studies were conducted to address the difficulties participants faced when sojourning (Fantini, 2006; Matsumoto, et al., 2001; Matsumoto, LeRoux, Bernhard, \& Gray, 2004), living (Jenkins, 2008; Matsumoto, et al., 2003) or studying (Dombi, 2011; Tran, 2009) abroad.

Otherstudieswereconcerned with howeducationalsettingsmaycontributetothe development ofICC(Jenkins, 2008; Kramsch,2010; Menyhei,2016;Xiao\&Petraki, 2007). All studies analyzed data on ICC; however, there are important differences in the ways they conceptualize and assess ICC. As there are many terminological and conceptual inconsistencies, the focus is on instruments that are relevant to the present study: they use similar constructs, or employ analogous methods or survey similar participants.

Arasaratnam (2009) used an instrument to measure participants' ICC based on Spitzberg and Cupach's (1984) construct of communication behavior that is both effective and appropriate. ICC was measured along three dimensions: cognitive, behavioral and affective. The following items constitute her measure: (1) attitudes towards other cultures (ATOC), (2) ethnocentrism, (3) motivation, (4) interaction involvement, (5) intercultural communication competence (ICC). Participants of the study $(\mathrm{N}=302)$ were students of a large Australian university, representing diverse cultures. Data were subjected to regression analysis, factor analysis and correlation analysis. The findings revealed positive relationships between ICC and ATOC, ICC and motivation, and ICC and interaction involvement; a negative correlation was found between ICC and ethnocentrism. The results from the regression indicated that ATOC, motivation, and interaction involvement were all predictors of ICC.

Matsumoto and his associates completed a series of studies on Japanese sojourners to the US (Matsumoto et al., 2001,2003, 2004) to uncover differences in the potential for intercultural adjustment using their own instrument, the Intercultural Adjustment Potential Scale (ICAPS). The ICAPS is based on the assumption that intercultural conflict is inevitable and adjustment depends on the ability to manage conflicts well (Matsumoto, et al., 2004). The instrument was used to predict how participants would respond to their new environment and how well they could adopt to new circumstances. Their findings were in accordance with theoretical assumptions about some psychological components necessary for successful intercultural adjustment, especially concerning emotion regulation, openness, flexibility and creativity (Matsumoto, et al., 2001, p. 505).

Ying (2002) also studied Asians temporarily residing in North America. Her participants were Taiwanese university students studying in the U.S. She hypothesized that students are more likely to form intercultural relationships if they have (1) a more extroverted personality, (2) a more robust knowledge about the host culture, (3) favorable attitudes towards befriending Americans, and (4) better communication skills in English. Ying measured personality, knowledge, attitudes, communication skills, social environment and social network composition. Results showed that students had some understanding of America, expressed equally positive attitudes towards forming relationship with American and Taiwanese peers, had moderate English competence, and their social networks mainly consisted of Chinese peers. More extroverted students reported more intercultural contacts and students understanding American culture more reported better relationships with Americans and more confidence in interacting.

In sum, personality and other learner characteristics were found to contribute to participants' predisposition to succeed in intercultural encounters. 


\subsection{Individual differences: Affective and communication variables}

Applied linguists have long been engaged in mapping the internal factors, which are responsible for differences in individuals' language learning (Clément \& Gardner, 2001, p. 21; Cohen \& Dörnyei, 2002; Dörnyei, 2005; Ellis, 1994). Individual differences (ID) were defined by Dörnyei as "dimensions of enduring personal characteristics that are assumed to apply to everybody and on which people differ by degree" $(2005, \mathrm{p} .4)$. In this section the most widely included affective and communication variables are discussed which are assumed to contribute to successful intercultural encounters.

Motivation, the force that drives people to pursue different ambitions, has long been in the center of attention (Dörnyei, 1990, 1994; Gardner \& Smythe, 1975; Gardner, 1985). Research shows that motivation is the second best predictor of L2 proficiency after aptitude (Dörnyei, 1998, 2001; Gardner, \& MacIntyre, 1993). In literature, language learners' motivation is either described along the intrinsic-extrinsic or the instrumental-integrative continuum (Dörnyei, 2005, pp. 73-80; Ellis, 1994, pp. 74-76).

Studies on Hungarian EFL learners' motivation to learn English found that students' main motives were intrinsic and instrumental. These results may be rooted in the specific contexts of these studies. The privileged position of English in Hungary (Nikolov 2002, 2003, 2007; Nikolov \& Józsa, 2003) contributes to students' underlying beliefs that it is in their own interest to learn this global language. This accounts for instrumental motivation: in a foreign language (FL) learning context students' main concern is not integrating, but making use of the language.

Attitudes have also been found to be strongly related to language learning success (see Dörnyei, Csizér, \& Németh, 2006; Ellis, 1994; Gardner, 1985). Attitudes include learners' beliefs and feelings towards the target language speakers, culture, and the social value of language learning. Increased opportunities for intercultural interactions are often perceived to have beneficial effects on learners' attitudes as they may result in an "enhanced understanding of the target language culture and a more sympathetic attitude to native speakers" (Coleman, 1997, p. 7). Previous research has shown that time spent in an English speaking country (Nagy, 2008) or in a foreign country (Dombi, 2011; Fantini, 2006) significantly enhances students' attitudes and openness towards other cultures, thus fostering ICC.

Ample studies have addressed the effect of intercultural contact on learners' attitudes towards the target culture, motivation and their language proficiency (Csizér \& Dörnyei, 2005; Csizér \& Kormos, 2008; Szaszkó, 2010). Attitudes towards speakers of a language most often determine attitudes towards the target language (Dörnyei, Csizér, \& Németh, 2006), and thus it also has an impact on motivation to learn the language. Studies have also emphasized that extensive intercultural contact raised participants' awareness towards intercultural issues and contributed to the development of favorable attitudes towards other cultures (Csizér \& Kormos, 2009; Szaszkó, 2010).

Apart from affective variables, certain communication variables may also contribute to individuals' success in intercultural interactions. The most often studied communication variable is willingness to communicate (WTC). Research on WTC derives from communication research in the native language. The construct proposed by McCroskey (1992) defines WTC as the probability that an individual would initiate a conversation if there were an opportunity. McCroskey and Richmond (1990) suggested that WTC in individuals' mother tongue is likely to be a personality trait, whereas in case of language learners, a more complex understanding of WTC is needed, since it is to a great extent situationally conditioned and involves a wide range of feelings. 
Two other communication variables are closely associated with WTC: communication apprehension (CA) and perceived communicative competence (PCC) (MacIntyre, 1994). In McCroskey's definition, CA is the "level of fear or anxiety" that individuals associate with interpersonal communication (1992, p. 1). Thus, conceptually, CA is similar to foreign language anxiety.

The way individuals assess their own L2 communication abilities is also of importance. Findings of previous studies on communication in L2 suggest that students' PCC significantly impacted their communication behavior. Studies have consistently shown a relationship between CA, PCC and WTC both in the mother tongue (McCroskey \& Richmond, 1990) and in a L2 (MacIntyre, Baker, Clément, \& Donovan, 2003; Nagy, 2008, 2009; Yashima, Zenuk-Nishide \& Shimizu, 2004).

In the Hungarian context, Nagy (2009) conducted a study on English majors' WTC in EFL. Her statistical analysis revealed that only learners' self-perceived proficiency influenced their WTC, whereas language anxiety was not directly related to the construct. However, learners' communicational anxiety was significantly related to their perceived competence. WTC had no direct relationship with actual L2 behavior; thus, high level of WTC did not result in actual use of EFL in real life situations.

\section{A study on EFL learners' ICC}

\subsection{Aim}

This study aimed to build and test a model of EFL language learners' intercultural communicative competence in relation to other learner variables in order to find out how certain individual difference variables influence the way language learners behave in intercultural situations.

The study addressed the following research questions:

RQ1: How does ICC relate to participants' affective ID variables?

RQ2: How does ICC relate to other communication variables?

RQ3: How does the frequency of IC contact contribute to ICC?

RQ4: How can ICC be modeled in relation to other learner variables?

\subsection{Participants}

Participants were first-year B.A. students of English Studies at a large Hungarian university. Altogether 117 students filled in the questionnaire. Fifteen participants were excluded for various reasons (i.e. incomplete questionnaire, native speaker of English). Consequently, the final number of participants was 102 (female $n=71$, male $\mathrm{n}=31$ ). Background data on participants are presented in Table 1.

Table 1. Background data on participants.

\begin{tabular}{lccccc}
\hline & N & Mean & Min & Max & SD \\
\hline Age & 102 & 20.3 & 19 & 23 & 1.4 \\
Number of years studying English & 102 & 10.5 & 5 & 12 & 3.7 \\
$\begin{array}{l}\text { Number of years of intensive English language } \\
\text { learning }\end{array}$ & 102 & 5.9 & 5 & 7 & 3.2 \\
\hline
\end{tabular}


As Table 1 presents, participants' average age was 20.3 years, they had been learning English for an average of 10.5 years, out of which 5.9 years were devoted to intensive language learning (more than 5 hours/week).

\subsection{Instrument and procedures}

In order to better understand how individual differences interact with students' ICC, a questionnaire was designed and piloted (Dombi, 2013). The questionnaire comprised five sections, aiming to elicit data on different individual difference and communication variables.

Section I was made up of nine items on willingness to communicate (WTC) to which participants needed to answer by giving percentage values, 0 meaning they are absolutely unwilling to act as described by the statement, 100 meaning they are absolutely willing to.

Section II included 18 self-assessment items: nine on perceived intercultural communicative competence (PICC) and nine on perceived communicative competence (PCC). Participants needed to give their answers in percentages, indicating how competent they believe they were in the situations described by the statements, 0 meaning absolutely incompetent, 100 meaning absolutely competent.

Section III comprised 18 items on communication apprehension (CA). Participants were requested to indicate how much they agreed with the statements on a five-point Likert scale ranging from 5 (strongly agree) to 1 (strongly disagree).

Section IV consisted of 56 items on various affective aspects and ICC. This section combined various scales: on motivation (MOT) on perceived L2 competence (PL2), and on intercultural contact (ICO). This section also comprised 23 items on ICC: seven on knowledge, seven on skills and nine on attitudes. Participants indicated how much they agreed with the statements on a 5-point Likert scale (5: strongly agree, 1: strongly disagree).

Section $V$ elicited data on participants' language learning background.

Table 2 provides a list acronyms used to refer to the variables.

Table 2. Acronyms used in the study

\begin{tabular}{ll}
\hline Acronym & Variable \\
\hline WTC & willingness to communicate \\
PICC & perceived intercultural communicative competence \\
PCC & perceived communicative competence \\
CA & communication apprehension \\
ICC & intercultural communicative competence \\
MOT & Motivation \\
PL2 & perceived L2 competence \\
ICO & intercultural contact \\
\hline
\end{tabular}

The questionnaires were administered in April, 2011 at the university under consideration. Taking part in this study was voluntary, and all first-year students enrolled to a compulsory English language development course gave their informed consent. The filling in the questionnaires lasted 30 minutes and was supervised by the author. For the statistical analysis SPSS 14.0 and AMOS 4.0 (Arbuckle, 1999) were used. 


\subsection{Results}

First, principal component analysis was performed. The scales constituted principal components; as confirmed by the reliability checks. Alpha values of the scales are presented together with the results in Table 3.

Table 3. Performance scores on the scales

\begin{tabular}{|c|c|c|c|c|c|c|}
\hline & $\mathbf{N}$ valid & N missing & Min & Max & Mean & SD \\
\hline $\begin{array}{l}\text { ICC } \\
\text { (Alpha=70) } \\
\text { 5-point } \\
\text { Likert-scale }\end{array}$ & 102 & 0 & 2.52 & 4.35 & 3.48 & .39 \\
\hline $\begin{array}{l}\text { PICC } \\
(\text { Alpha=.70) } \\
0-100 \%\end{array}$ & 102 & 0 & 34.11 & 100 & 76.48 & 13.42 \\
\hline $\begin{array}{l}\text { WTC } \\
\text { (Alpha }=.85 \text { ) } \\
0-100\end{array}$ & 102 & 0 & 40.56 & 100 & 78.39 & 16.09 \\
\hline$\overline{C A}$ & 102 & 0 & 1.56 & 4.61 & 2.76 & .79 \\
\hline
\end{tabular}

(Alpha=.93)

5-point

Likert-scale

\begin{tabular}{lllllll}
\hline MOT & 102 & 0 & 3.36 & 5.00 & 4.44 & .41
\end{tabular}

(Alpha $=.71)$

5-point

Likert-scale

\begin{tabular}{lllllll}
\hline PCC & 102 & 0 & 41.11 & 100 & 80.33 & 15.39
\end{tabular}

(Alpha $=.90)$

0-100\%

\begin{tabular}{lllllll}
\hline ICO & 102 & 0 & 1.67 & 5.00 & 3.80 & .62
\end{tabular}

(Alpha=.74)

5-point

Likert-scale

\begin{tabular}{lllllll}
\hline PL2 & 102 & 0 & 2.00 & 4.71 & 3.37 & .66
\end{tabular}

(Alpha=.78)

5-point

Likert-scale

Two scales elicited information on participants' intercultural communicative competence: the ICC scale and the PICC scale. However, in drawing the model one variable on ICC was needed. To have one single variable instead of these two, a linear transformation was used.

Final values for ICC are presented in Table 4.

Table 4. Students' scores on the combined ICC (ICC_C, measure 0-100)

\begin{tabular}{lcccccc}
\hline & $\mathbf{N}$ & $\mathbf{N}$ missing & Min & Max & Mean & SD \\
\hline ICC_C & 102 & 0 & 41.0 & 90.20 & 69.34 & 9.71 \\
\hline
\end{tabular}




\subsubsection{RQ1: How does ICC relate to participants' affective ID variables?}

To find out more about the relationship between ICC scores and affective individual differences, the Pearson product-moment correlation coefficient was computed for participants' combined ICC scores, their WTC, CA and MOT. The analysis revealed a significant $(\mathrm{p}<.01)$ correlation between ICC and the affective variables WTC $(r=.529)$, CA1 $(r=-.627)$ and MOT $(r=.298)$. Thus, in line with previous expectations, sound relationships were detected between WTC, CA and ICC, and low, yet still significant relationships between MOT and ICC.

To get a clearer picture on the relationships among these variables, stepwise regression analysis was performed. This type of statistical analysis seeks to explain the variance in the level of one variable on the basis of the level of other variable(s). Hence, the analysis was meant to find out how much variance in individuals' ICC scores can be explained by the variables WTC, CA and MOT. Thus, ICC was entered as a dependent variable, and WTC, CA and MOT were entered as independent variables (predictors). The variables were entered step-wise, in the following order: CA, WTC, and MOT.

Results suggest that the predictors entered this way explained a significant amount of variance in students' ICC scores (F1,100 = 64.68; $p<.01)$. As for the dependent variables, CA explained 39 percent of variance in participants' ICC scores $\left(\mathrm{R}^{2}\right.$ adj $=.387$ for $\left.C A\right)$, WTC explained an additional six percent $\left(\mathrm{R}^{2} \mathrm{adj}=.450\right.$ for CA and WTC), whereas the inclusion of MOT into the model resulted in an additional two percent of explained variance $\left(\mathrm{R}^{2} \mathrm{adj}=.467\right.$ for the three dependent variables).

\subsubsection{RQ2 and RQ3: How does ICC relate to other communication variables and to the frequency of intercultural contacts (ICO)?}

In a second round, similarly to previous steps, correlation analysis and regression analysis were carried out to map the relationship between participants' ICC scores and their communicative profile, i.e. their perceived communicative competence (PCC), their perceived L2 competence (PL2) and the frequency of their intercultural contacts (ICO).

The analysis revealed significant $(\mathrm{p}<.01)$ relationships between each of the variables and ICC. PCC had the highest correlation ( $r=.709)$ with ICC, and PL2 also had a rather high value $(r=.610)$. The ICO variable had somewhat more modest, yet still significant correlation $(\mathrm{r}=.432)$ with ICC.

Regression analysis provided an insight into the relationship between these individual difference variables and ICC. Similarly to previous steps, ICC was entered as a dependent variable, whereas the other individual difference variables were entered stepwise as independent variables, first PCC, then PL2 and finally, ICO. However, the analysis excluded ICO and only tested the models with PCC and PL2, revealing that participants' ICO cannot explain any variance in their ICC scores.

Results reveal that PCC and PL2 explain a significant amount of variance in students' ICC scores $(\mathrm{F} 1,101=61.63 ; \mathrm{p}<.01)$. The dependent variable PCC explained almost 50 percent of variance in students' ICC scores ( $R^{2} a d j=.498$ for PCC), and PL2 explained an additional five percent $\left(\mathrm{R}^{2} \mathrm{adj}=.546\right.$ for PCC and PL2).

\subsubsection{RQ4: How can ICC be modeled in relation to other learner variables?}

Since correlation analysis shows only to what extent certain variables are related, but does not explain causation, a more complex statistical analysis was applied 
to get a better picture on participants' ICC in relation to the observed affective and communication variables. To achieve this, first a model of the cause-effect relationships of the observed variables was proposed, which could be tested as a second step. A type of structural equation modeling, path analysis, was used to test the hypothesized model. The proposed model was drawn up based on correlations presented above.

Based on these, a model was constructed (see Figure 1). In this model the affective variables WTC and CA and other communication variables PCC and PL2 were pictured as related; the affective variable MOT and the individual difference variable ICO were also presented as related. As regression analysis indicated that PCC, CA and WTC explained the most variance in ICC scores, a direct path was suggested from these variables to ICC. Even though regression analysis excluded ICO, a path from this variable to ICC was also proposed since the literature suggests that experience with the target culture fosters ICC. Correlation analysis also revealed a significant but moderate relationship between these two values.

As path models follow certain common drawing conventions (Schumacker \& Lomax, 2004) these conventions are used in Figures 1 to 4 . Observed variables are presented in rectangular boxes. Lines directed from one observed variable to another signal direct effects, whereas curved, double-headed lines denote covariance, meaning that the marked variables are correlated. Each dependent variable also has an error term, indicated by a circle around the error term (Byrne, 2010; Schumacker \& Lomax, 2004).

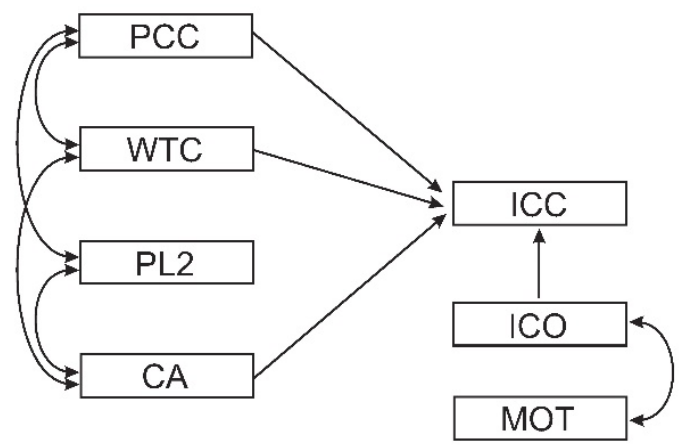

Figure 1. Proposed model of ICC

The proposed model's fit to the dataset was tested using AMOS 4.0, a computer program designed for structural equation modeling (SEM) (Arbuckle, 1999). There are numerous criteria for assessing model fit, including (1) $\chi^{2}$; (2) $\chi^{2}$ divided by the number of degrees of freedom; (3) goodness-of-fit index (GFI); (4) adjusted goodnessof-fit index (AGFI); (5) Bentler-Bonett normed fit index (NFI); (6) Tucker-Lewis coefficient (TLI); (7) root mean square error of approximation (RMSEA); (8) expected cross-validation index (ECVI); and (9) comparative fit index (CFI) (Loehlin, 2004; Raykov \& Marcoluides, 2006; Schumacker \& Lomax, 2004). These indices are meant to show how much the model deviates from the null hypothesis of no relationships between the constituents.

As for GFI, AGFI, NFI, TLI, CFI, values may be placed on a $0-1$ scale, 0 indicating no fit, whereas 1 indicates a perfect fit of the model. As for RMSEA, a value less than .05 indicates a good model fit. $\chi^{2} / \mathrm{df}$ ratio should not exceed 2 for the model to be accepted (Schumacker \& Lomax, 2004, pp. 82-83). The probability (p) value of the $\chi^{2}$ must exceed 05 , otherwise the model has to be rejected. All these fit measures are provided 
together with the tested and re-tested models. However, taking into consideration the relatively small sample size ( $\mathrm{N}=102)$, the RMSEA index is of crucial importance, as it is insensitive to sample size (Loehlin, 2004, p. 68). The proposed model was tested with AMOS 4.0 (Arbuckle, 1999), and the results with the standardized path coefficients and the goodness-of-fit measures are shown in Figure 2.

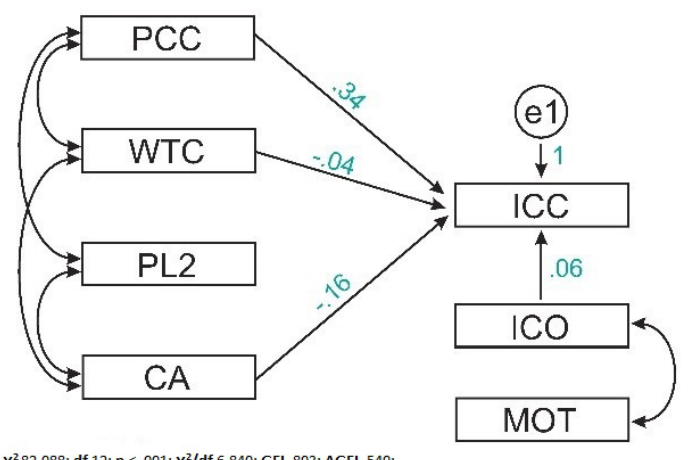

Figure 2. The proposed model tested.

As Figure 2 shows, the $\chi^{2}$ for the proposed model was 82.08 with 12 degrees of freedom, thus, $\chi^{2} / \mathrm{df}$ ratio was 6.84 , which was above the level of acceptance. However, not only was this value problematic with the initial model, but the probability did not exceed .001, so that the model significantly differed from the dataset and had to be rejected.

In building the second model, we relied on AMOS' suggestion that the path from WTC to ICC was not significant, and deleted it. Moreover, AMOS also recommended to make all the four dependent variables inter-correlated, so we changed the model to fit these suggestions. Furthermore, the path from ICO to ICC was also found to be insignificant. However, we decided to keep it for the time being, to check how this revised model worked. The revised model was re-submitted to analysis, and its results are shown in Figure 3.

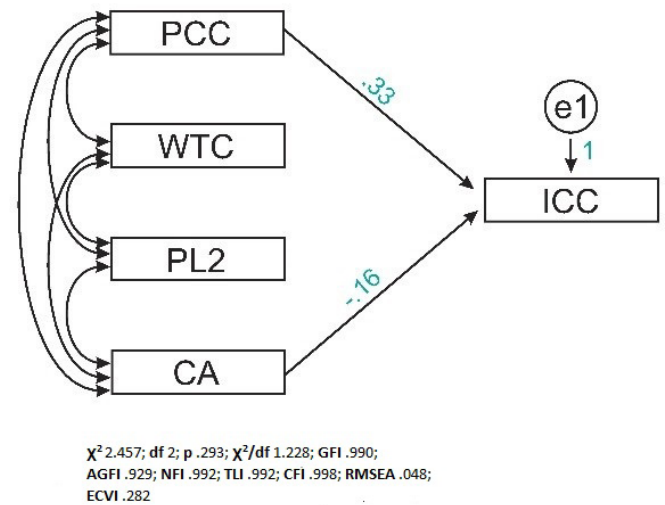

Figure 3. Revised model 
In the revised model all paths but the one from ICO to ICC were significant, and the correlation values between PCC, WTC, CA and PL2 were convincing (as presented in Figure 3). However, the goodness-of-fit measures were still unacceptable $\left(\chi^{2} / \mathrm{df}=\right.$ $3.75, p=<.001$, and RMSEA $=.165$ ). Thus, further revision of the model was necessary.

AMOS had previously suggested elimination of the path from ICO to ICC to gain better fit measures. As a result of this, it was concluded that in order to adequately model English majors' ICC, the variables ICO and MOT had to be excluded from the model. The final model consisted of the inter-correlated PCC, PL2, CA and WTC, with significant paths from PCC to ICC, and from CA to ICC (see Figure 4). The model was re-entered for analysis and was found to fit the dataset with very good goodness-of-fit indices: $\chi^{2} / \mathrm{df}$ ratio was 1.22 with a probability of .293 , and the RMSEA was .048 .

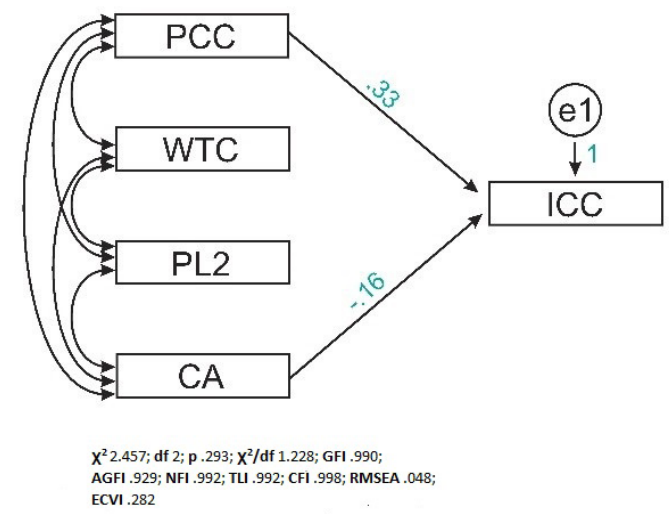

Figure 4. The final model.

\subsection{Discussion}

Findings concerning the relationship between affective variables revealed the strongest negative relationship between CA and ICC, indicating that anxiety is most likely to affect performance in intercultural situations. Willingness to communicate in English was also found to significantly correlate with ICC: the more ready students are to engage in communication, the more likely they are to be successful in such interactions. This relationship is rooted in the multi-faceted nature of the ICC construct: someone with high scores on the combined ICC scale has high scores on the ICC Attitudes and the Perceived ICC scales as well, both of which comprise items describing imagined interactions with members of other cultures. Thus, it is likely that the more eager students are to take part in such conversations, the more likely they develop positive attitudes towards others, which in turn, fosters their ICC.

The relationship between motivation and ICC was also significant; however, much weaker than the previous two affective variables. This finding shows similarities with findings of Szaszkó (2010) who found that in the case of Hungarian adult EFL learners, intercultural contact had more impact on their English communicative competence than their language learning motivation.

Regression analysis confirmed the assumption that anxiety is of utmost importance in intercultural encounters: it was found that most variance in students' ICC 
scores could be explained by their CA scores, and the addition of WTC and motivation did not explain significantly more variance in ICC. Revisiting the findings of previous studies in similar settings, more empirical evidence supports this result: debilitating anxiety, i.e. the extreme feeling of insecurity is a factor participants frequently mention as the major obstacle to success in intercultural encounters (Dombi, 2013; Menyhei, 2016; Nagy, 2009). Students in these studies reported feeling nervousness, apprehension or even panic when it came to speaking in English with members of other cultures. The findings of the present study confirm that the apprehension experienced when talking in English prevents students from extensive intercultural contacts, negatively influencing both their WTC and their motivation, thus affecting their ICC.

A strong relationship was found between perceived communication competence and ICC. However, the interpretation of this finding requires some caution: since correlation does not show which variable influences the other, this outcome can be interpreted in two different ways and they both make sense. We may assume that the students who thought they had better communication skills had higher ICC, as their better perceived communicative competence made them more self-confident, and thus more likely to take part in intercultural interactions, which, in turn, made them more experienced and competent in such situations. However, this can also work the other way around: higher ICC, i.e. more success in intercultural situations, can also boost students' self-confidence, making them believe they are good at communication in the target language.

Moreover, PCC and ICC were related, as ICC also has to do with communication: students who believe they are more competent communicators in English are likely to project the same competency in intercultural situations in which they communicate in English. This finding is supported by findings in Nagy's (2009) study: PCC was found to be more likely to influence students' communication behavior than their linguistic self-confidence (p. 92).

A more advanced statistical procedure, regression analysis, proved that PCC explained almost 50 percent in the variance of students' ICC scores, thus revealing PCC to be an important predictor of ICC. Students' perceived L2 competence was also found to be strongly related to their ICC. With regard to this variable, the relationship seems more straightforward (still not evident, as correlation alone is insufficient to establish a cause-effect relationship): students who believed they had better English proficiency were likely to score higher on ICC. This may be due to the fact that high level of perceived L2 competence, similarly to good PCC, helps students to be more confident and self-assured in interactions. However, since more students are in the average PL2 category than in the average PCC category, it can be observed that there are students who believe they are good at English, but fewer of them believe they are good at communication in English.

As for the last individual difference variable, ICO, the results showed a relatively high frequency of intercultural contact, which was not surprising, as the university town is known for the high number of foreign students.

Contrary to expectations, a significant, yet surprisingly weak relationship was found between students' ICC and the frequency of their intercultural contact. Moreover, stepwise regression analysis excluded the ICO variable and concluded that it did not explain variance in students' ICC scores. These results were rather unexpected, as one would assume that students' exposure to foreign cultures through contact contributes to their ICC to a great extent. Nagy's findings (2008) on English majors who previously worked as au-pairs in the UK revealed that as a result of their first-hand experiences 
with members of other cultures, participants were ready to drop their previous stereotypes, and became more aware of the importance of cultural diversity. Similarly, Fantini (2006) found that exchange students' extended contact with local residents in Ecuador was among the factors mostly contributing to their enhanced ICC. In this study, however, there was no empirical evidence to support the claim that the frequency of intercultural contact had a significant impact on ICC. Since Fantini's (2006) and Nagy's (2008) study surveyed participants who spent time in a foreign country, findings may imply that extensive contact with a foreign culture away from one's home environment could result in these beneficial outcomes, whereas the impact of foreign contact on one's ICC while residing at home may be more limited.

The most important finding of the SEM analysis was that the initially suggested model (Figure 1) of English majors' ICC did not provide acceptable goodness-of-fit indices, and had to be rejected. The underlying problem with the proposed model was that it hypothesized direct relationship between WTC and ICC, based on findings of the correlation and regression analyses. Based on these results it was reasonable to assume that the more willing students are to take part in English conversations, the more likely it is for them to develop their intercultural communicative competence. The analysis, however, rejected this hypothesis, as the goodness-of-fit values gradually improved after deleting the direct path from WTC to ICC.

Willingness to communicate, however, remained a part of the model, although in a slightly modified position. The revised models contain WTC as a part of a chain of inter-correlated variables, including perceived L2 competence, perceived communication competence and anxiety. Based on findings of Nagy (2009) with a very similar population, the original model did not hypothesize a significant relationship between WTC and PL2; however, SEM revealed that a revised model with such correlation fits the dataset to a much greater extent. This result may be construed as students with better perceived L2 competence tend to be more satisfied with themselves and less insecure in communication; thus, they are more likely to engage in interactions in English. This leads to the interpretation that not only the perceived level of proficiency plays a role here, but perceived communication competence does so as well. The better communicators students believe they are, the more likely it is for them to take part in interactions in English; this is a finding in line with Nagy's (2009) results.

Important characteristics of the initial model which were maintained throughout the revisions are the direct paths from perceived communicative competence and communication apprehension to ICC. The fact that these paths were found to be significant confirms the findings of regression analyses: these are the two most important predictors of ICC.

The initial model, as well as the first two revised models suggested a further path that finally proved to be non-significant: the direct path between the frequency of intercultural contact and ICC. As other empirical studies (Dombi, 2011; Matsumoto, et al., 2001, 2003; Nagy, 2008) suggest that acquaintance with members of other cultures makes students more interculturally-minded and successful in intercultural situations, this variable was included in the model, even though the regression analysis did not show significant predictive value for it. Initially, it was proposed that students' motivation to learn English and the frequency of their intercultural contact were related: motivated students were thought to seek intercultural contact for various reasons, such as practicing the language by meeting speakers of English. Frequent intercultural contact, on the other hand, was hypothesized to sustain and further increase students' motivation to learn English. Surprisingly, this link was disproved. 
Not only did SEM reveal that these variables were not directly related to ICC, but it was also suggested that they had nothing to do with the construct, and consequently had to be removed from the model.

The final model shows that the two variables directly influencing ICC were (1) perceived communicative competence in a positive and (2) communication apprehension in a negative way. This means that students with a more confident self-image have higher ICC, most probably because this confidence assures them in intercultural situations and helps them overcome difficulties or breakdowns in communication. This finding reveals that learners' self-image is of utmost importance: the PCC scale did not measure actual communication competence, but perceived communication competence. Therefore, there is no evidence that students who believe they are good communicators are actually good or not. However, it seems that the belief of being good at communicating in English allows these students to take advantage of intercultural situations and develop their ICC.

Highly anxious students, on the other hand, fear engaging in intercultural situations, possibly due to their lack of self-confidence. Over-anxious students trying to avoid interactions deprive themselves of the benefits of learning from such encounters and have fewer chances to develop their ICC. As a result, special attention should be paid to help anxious students overcome their fear to communicate in English.

\section{Conclusion}

One of the main aims of the study was to draw a theoretically sound and empirically based model that adequately presents English majors' ICC. This was achieved through performing structural equation modeling on the dataset. The final model presents four inter-correlated individual difference variables, WTC, CA, PL2 and PCC with direct paths from PCC and CA to ICC, suggesting that students' willingness to use English, their ideas about their own performance and their apprehension from communication situations are strongly related, and out of these variables perceived communication competence and communication apprehension directly affect ICC.

This indisputably has a pedagogical implication: knowing the variables influencing ICC may help instructors to tailor their teaching so as to address the individual differences accounting for variation in ICC.

It was shown that students' ICC was mostly affected by their anxiety. This result echoed findings of previous studies conducted with similar English language majors (Nagy, 2009; Tóth, 2007, 2011). It would be crucial to reduce learners' nervousness about speaking in English, since their anxiety has negative effects on their development: it debilitates their performance, and most often prevents them from interacting with others in English. Instructors should pay special attention to reducing learners' anxiety in classrooms, which can be achieved by creating a relaxed and friendly atmosphere free of competition. Raising students' awareness about negative effects of anxiety is also crucial, as it may induce more conscious actions.

Findings also suggest that students' self-image as communicators (their perceived communicative competence and their perceived L2 competence) are of utmost importance: if students believe they are good communicators in English, they are more likely to be self-confident and are more likely to take part in intercultural encounters. Thus, instructors should help students achieve a realistic self-image about their performance in English and support them if they lack self-confidence. 


\section{References}

Arbuckle, J. L. (1999). Amos (Version 4.0) [Computer Software]. Chicago: SPSS.

Arasaratnam, L. A. (2009). The development of a new instrument of intercultural communication competence. Journal of Intercultural Communication, 20. Retrieved 21 May 2011 from http://www.immi.se/intercultural/nr20/ arasaratnam.htm

Byram, M. (1997). Teaching and assessing intercultural communicative competence. Clevedon: Multilingual Matters.

Byrne, B. M. (2010). Structural equation modeling with AMOS: Basic concepts, applications, and programming. New York: Routledge.

Canale, M. (1983). From communicative competence to communicative language pedagogy. In J. C. Richards, \& R. W. Schmidt (Eds.), Language and communication (pp. 2-27). London: Longman.

Canale, M., \& Swain, M. (1980). Theoretical bases of communicative approaches to second language teaching and testing. Applied Linguistics, 1, 1-47.

Clément, R., \& Gardner, R. C. (2001). Second language mastery. In H. Giles, \& W. P. Robinson (Eds.), Handbook of language and social psychology (pp. 489-504). London: Wiley.

Cohen, A. D., \& Dörnyei, Z. (2002). Focus on the language learner: Motivation, styles, and strategies. In N. Schmitt (Ed.), An introduction to applied linguistics (pp. 170-190). London: Edward Arnold.

Coleman, J. A. (1997). Residence abroad within language study. Language Teaching, $30(1), 1-20$.

Council of Europe (2001). Common European framework of reference for languages: Learning, teaching, assessment. Cambridge: Cambridge University Press.

Csizér, K., \& Kormos, J. (2008). The relationship of inter-cultural contact and language learning motivation among Hungarian students of English and German. Journal of Multilingual and Multicultural Development, 29, 30-48.

Csizér, K., \& Kormos, J. (2009). Modeling the role of inter-cultural contact in the motivation of learning English as a foreign language. Applied Linguistics, 30, 166-185.

Csizér, K., \& Dörnyei, Z. (2005). The internal structure of language learning motivation and its relationship with language choice and learning effort. Modern Language Journal, 89, 9-36.

Dombi, J. (2011). Exploring Korean EFL students' intercultural experiences. Presented at the XX. International Grastyán Conference, Pécs, Hungary

Dombi, J. (2013). A mixed-methods study on English majors' intercultural communicative competence. (Unpublished doctoral dissertation). University of Pécs. Pécs

Dörnyei, Z. (1990). Conceptualizing motivation in foreign language learning. Language Learning, 40, 45-78.

Dörnyei, Z. (1994). Motivation and motivating in the foreign language classroom. The Modern Language Journal, 78, 273-283.

Dörnyei, Z. (1998). Motivation in second and foreign language learning. Language Teaching, 31, 117-35.

Dörnyei, Z. (2001). Teaching and researching motivation. England: Pearson Education Limited.

Dörnyei, Z. (2005). The psychology of the language learner: Individual differences in second language acquisition. Mahwah, NJ: Lawrence Erlbaum. 
Dörnyei, Z., Csizér, K., \& Németh, N. (2006). Motivation, language attitude and globalisation: A Hungarian perspective. Clevedon: Multilingual Matters.

Ellis, R. (1994). The study of second language acquisition. Oxford: Oxford University Press.

Fantini, A. (2006). Exploring and assessing intercultural competence. Final report. Brattleboro, VT: EIL. Retrieved 13th September 2010 from http://www. experiment.org/documents/FinalGSIResearchReport12.06.pdf

Gardner, R. C. (1985). Social psychology and second language learning: The role of attitude and motivation. London: Edward Arnold.

Gardner, R., \& MacIntyre, P. D. (1993). A student's contributions to second-language learning. Part 2: Affective variables. Language Teaching, 26, 1-11.

Gardner, R.C., \& Smythe, P.C. (1975). Motivation and second language acquisition. The Canadian Modern Language Review, 31, 218-230.

Jenkins, S. (2008). Adopting an intercultural approach to teaching English as an international language. Essential teacher, 5(4), 19-21.

Kramsch, C. (2010). The symbolic dimension of the intercultural. Plenary delivered at the Intercultural communication conference, University of Arizona. Manuscript of speech sent via email on 24 January, 2010.

Loehlin, J. C. (2004). Latent variable models: An introduction to factor, path, and structural analysis. Hillsdale, NJ: Laurence Erlbaum.

MacIntyre, P. D. (1994). Variables underlying willingness to communicate: A casual analysis. Communication Research Reports, 11, 135-142.

MacIntyre, P. D. (1999). Language anxiety: A review of the research for language teachers. In D. J. Young (Ed.), Affect in foreign language and second language learning: A practical guide to creating a low anxiety classroom atmosphere (pp. 24-45). Boston, MA: McGraw-Hill College.

MacIntyre, P. D., \& Charos, C. (1996). Personality, attitudes, and affect as predictors of second language communication. Journal of Language and Social Psychology, 15(1), 3-26.

MacIntyre, P. D., Baker, S., Clément, R., \& Donovan, L. A. (2003). Talking in order to learn: Willingness to communicate and intensive language programs. The Canadian Modern Language Review, 59(4), 580-607.

Mackey, A., \& Gass, S. (2005). Second language research: Methodology and design. Mahvah, NY: Lawrence Erlbaum.

Matsumoto, D., LeRoux, J. A., Ratzlaff, C., Tatani, H., Uchida, H., Kim, C., \& Araki, S. (2001). Development and validation of a measure of intercultural adjustment potential in Japanese sojourners: The Intercultural Adjustment Potential Scale (ICAPS). International Journal of Intercultural Relations, 25, 483-510

Matsumoto, D., LeRoux, J. A., Iwamoto, M., Choi, J. W., Rogers, D., Tatani, H., \& Uchida, H. (2003). The robustness of the Intercultural Adjustment Potential Scale (ICAPS). International Journal of Intercultural Relations, 27, 543-562.

Matsumoto, D., LeRoux, J. A., Bernhard, R., \& Gray, H. (2004). Personality and behavioral correlates of intercultural adjustment potential. International Journal of Intercultural Relations, 28, 281-309.

McCroskey, J. C. (1982). Introduction to rhetorical communication. Englewood Cliffs, NJ: Prentice-Hall.

McCroskey, J. C. (1992). Reliability and validity of the willingness to communicate scale. Communication Quarterly, 140, 16-25.

McCroskey, J. C., \& Richmond, V. P. (1987). Willingness to communicate. In J.C. McCroskey, \& J.A. Daly (Eds.), Personality and interpersonal communication (pp. 129-156). Newbury Park, CA: Sage. 
McCroskey, J. C., \& Richmond, V. P. (1990). Willingness to communicate: Differing cultural perspectives. The Southern Communication Journal, 56, 72-77.

Menyhei, Zs. (2016). Developing English majors' intercultural communicative competence in the classroom: We have learnt (...) how much more we need to learn about Intercultural Communication. (Unpublished doctoral dissertation). University of Pécs, Pécs.

Nagy, B. C. (2008). Linguistic and socio-cultural outcomes of the Au Pair experience in the United Kingdom. Language and Intercultural Communication, 8(3), 172192.

Nagy, B. C. (2009). 'To will or not to will': Exploring advanced EFL learners' willingness to communicate in English. (Unpublished doctoral dissertation) University of Pécs, Pécs.

Nikolov, M., \& Józsa, K. (2003). Az idegen nyelvi készségek fejlettsége angol és német nyelvböl a 6. és 10. évfolyamon a 2002/2003-as tanévben. [Foreign language competence in English and German in grades 6 and 10 in the 2002/2003 academic year.] Budapest: OKÉV.

Nikolov, M. (2002). Issues in English language education. Bern: Peter Lang AG.

Nikolov, M. (2003). Az idegennyelv-tanítás megújulásának hatásai. [Effects of renewing foreign language teaching.] Új Pedagógiai Szemle, 53(3), 46-57.

Nikolov, M. (2007). A magyarországi nyelvoktatás-fejlesztési politika: Nyelvoktatásunk a nemzetközi trendek tükrében.[Hungarian foreign language development policy. Our language teaching and international trends.] In I. Vágó (Ed.), Fókuszban a nyelvtanulás (pp. 43-72). Budapest: Oktatáskutató és Fejlesztő Intézet.

Raykov, T., \& Marcoulides, G. A. (2006). A first course in structural equation modeling. Mahwah, NJ: Lawrence Erlbaum.

Schumacker, R. E., \& Lomax, R. G. (2004). A beginner's guide to structural equation modeling. Mahwah, NJ: Lawrence Erlbaum.

Spitzberg, B. H., \& Cupach, W. R. (1984). Interpersonal communication competence. Beverly Hills, CA: Sage.

Szaszkó, R. (2010). The effects of intercultural contact on adult Hungarians' motivation for learning English as a foreign language. (Unpublished doctoral dissertation). Eötvös Loránt University, Budapest.

Tóth, Zs. (2006). First-year English majors' perceptions of the effects of foreign language anxiety. In M. Nikolov, \& J. Horváth (Eds.), UPRT 2006: Empirical studies in English applied linguistics (pp. 25-37). Pécs: Lingua Franca Csoport.

Tóth, Zs. (2007). Foreign language anxiety: A study of first-year English majors. (Unpublished doctoral dissertation). Eötvös Lóránt University, Budapest.

Tóth, Zs. (2011). Foreign language anxiety and advanced EFL learners: An interview study. WoPaLP, 5, 39-40.

Tran, L. T. (2009). Making visible hidden intentions and potential choices: International students in intercultural communication. Language and Intercultural communication, 9(4) 271-284.

Van Ek, J. A. (1986). Objectives of foreign language learning. Volume I: Scope. Strasbourg: Council of Europe, Publications Section.

Xiao, H., \& Petraki, E. (2007). An investigation of Chinese students' difficulties in intercultural communication and its role in ELT. Journal of Intercultural communication, 13, Retrieved 20 May 2010 from http://www.immi.se/ intercultural/nr13/petraki.htm 
Yashima, T., Zenuk-Nishide, L., \& Shimizu, K. (2004). The influence of attitudes and affect on willingness to communicate and second language communication. Language Learning, 54, 119-152.

Ying, Y. (2002). Formation of cross-cultural relationships of Taiwanese international students in the United States. Journal of Community Psychology, 30(1), 45-55. 